\title{
Educação Permanente em Saúde: Produzindo Sentidos e Qualificando a Gerência dos Centros de Especialidades Odontológicas Estaduais em Sergipe.
}

Couto, Graziane Ribeiro; Barbosa, Aldenísia A. Albuquerque; Cabral, Marlos Cesar Bomfim; Cerqueira, Rosiane Azevedo da S.; Iung, Andreia Maria Borges; Travassos, Daniele de Araújo

Funesa - Fundação Estadual de Saúde de Sergipe — graziane.funesa@gmail.com

O presente trabalho tem o desiderato de mencionar um projeto de intervenção que foi apresentado à Universidade Federal do Rio Grande do Norte como requisito para conclusão do Curso de Especialização em Gestão do Trabalho e da Educação na Saúde uma proposta de Educação Permanente para qualificar e humanizar as ações de gestão dos CEOs estaduais em Sergipe, produzindo novos significados ao processo de trabalho das equipes e ao arranjo organizacional do modelo de atenção secundária à saúde bucal. o público-alvo deste projeto são cirurgiões dentistas que atuam no cargo de gerente dos CEOs de Boquim, Laranjeiras, Propriá, São Cristóvão, Tobias Barreto e em breve no CEO recém-implantado de Nossa Senhora da Glória, municípios que sediam tais unidades com o processo de regionalização no cenário do estado de Sergipe. para tanto, será implantado o processo de Educação Permanente em Saúde, com a utilização de metodologias ativas de aprendizagem, visando incorporar novas ferramentas pedagógicas e operacionais e fortalecer o trabalho desenvolvido pelos gerentes. Os CEOs estaduais de Sergipe compõem uma rede de serviços especializados em saúde bucal, ofertados complementarmente às ações executadas no âmbito da atenção básica de diversos municípios sergipanos, atendendo aos pressupostos de qualidade, humanização, eficiência e resolutividade, e obedecendo aos preceitos do Sistema Único de Saúde. Pretende-se, portanto, contribuir para a consolidação da rede especializada em saúde bucal no estado de Sergipe, em consonância com o padrão de eficiência e resolutividade deferido pela Política Nacional e Estadual de Saúde Bucal.

Couto, Graziane Ribeiro; Barbosa, Aldenísia A. Albuquerque; Cabral, Marlos Cesar Bomfim; Cerqueira, Rosiane Azevedo da S.; lung, Andreia Maria Borges; Travassos, Daniele de Araújo. Educação Permanente em Saúde: Produzindo Sentidos e Qualificando a Gerência dos Centros de Especialidades Odontológicas Estaduais em Sergipe.. In: Anais do Congresso Internacional de Humanidades \& Humanização em Saúde [= Blucher Medical Proceedings, num.2, vol.1]. São Paulo: Editora Blucher, 2014. ISSN 2357-7282

DOI 10.5151/medpro-cihhs-10684 